\title{
What have we learned on adolescent transitions?
}

\author{
Thierry Gagné ${ }^{1,2}$
}

Received: 7 January 2019/Accepted: 17 January 2019/Published online: 8 February 2019

(C) Swiss School of Public Health (SSPH+) 2019

The IJPH Special Issue on Adolescent Transitions presents new evidence on health issues emerging during teen years, and the ways in which these may progress over the life course. Findings support the central roles of family and school and shed light on the new social changes contributing to adolescent health, including the expansion of media technologies and the progression of income inequalities.

Adolescent research, by definition, focuses on the stage between childhood and adulthood around the second decade of life (Johnson et al. 2011). This definition, which is key in orienting youth policies and interventions, has been challenged on two fronts. First, many of the health-related trajectories emerging in this life-course stage progress beyond the second decade of life and include (1) mortality from accidents and suicide, (2) morbidity from obesity, stress, and mental disorders, and (3) behaviours such as tobacco smoking and problem drinking (PHAC 2011). Second, these health-related trajectories occur within broader social transitions in education, employment, family, and housing arrangements. The traditionally protracted and linear "transition to adulthood" has been elongating and diversifying at an accelerating pace (Furstenberg 2015). This means that, for most, social transitions continue well into the third decade of life. Illustrating this in this issue, Baggio et al. (2018) found that, at the age of 20, relatively few youths perceived themselves as adults and completed adult milestones, i.e. finishing education, leaving parents' household, gaining financial independence, having a stable relationship, and having children. When

This editorial is part of the special issue "Adolescent transitions".

Thierry Gagné

thierry.gagne@umontreal.ca

1 École de santé publique de l'Université de Montréal (ESPUM), Université de Montréal, Montréal, Canada

2 Department of Epidemiology and Public Health (DEPH), University College London, 1-19 Torrington Place, Room 536, London WC1E 7HB, UK followed to the age of 25 , the authors found that these perceptions and transitions had still not changed much.

Research on adolescent transitions, therefore, circumscribes the development of health and social outcomes that occur over the second and third decades of life, and the social changes that further shape these outcomes. Outside public health, other scientific disciplines have begun adapting to the elongating transitions traditionally associated with adolescence. In social sciences, Johnson et al. (2011) argued that a new research generation needed to address beyond the second decade of life the relation between adolescence and other life-course stages surrounding it, including young adulthood. In medicine, Sawyer et al. (2018) argued that adolescent research should extend its focus to the age of 24 to account for the delayed timing of role transitions.

Against this background, one crosscutting issue across this special issue concerned whether submissions actually informed the transitions in health and social outcomes experienced during this period. A significant portion of studies produced cross-sectional analyses of adolescent outcomes, limiting insights into temporal processes within and between life-course periods. Alongside these methodological considerations, the lack of a theoretical perspective focusing on transitions also limited the interpretation of some findings. For instance, Masa et al. (2018) brought forward new evidence on the role of food insecurity on sexual risk taking practices using two samples with mean ages of 17 and 22, yet missed the opportunity to discuss differences in keeping with the different life periods associated with these two age groups.

The small proportion of studies focused on transitions may be explained in part by the number of papers coming from the Health Behaviour in School-aged Children (HBSC) network, whose members were also responsible for the creation and stewardship of the special issue. The design of the HBSC survey, which recruits a number of 11-, 13-, and 15-year-olds in cross sections every four years, precludes researchers from fully disentangling (1) the longitudinal processes underlying differences between age groups and (2) the long-term consequences of 
outcomes observed in these age groups. These limitations, however, do not imply that data from these surveys cannot be used to study change in adolescent outcomes. Demonstrating this, De Looze et al. (2018) made brilliant use of the repeated nature of the survey to study the spread of media technologies and its impact on adolescents' substance use over time.

In summary, research on adolescent health is challenged by the social changes that have transformed its object of scientific enquiry from a relatively contained life stage to an increasingly complex life period. Returning to the call of the special issue, one may argue that the attention devoted to transitions here highlights the "youthfulness" of the interface between public health, adolescent research, and life-course studies. Papers in the special issue contributed to this body of work with the provision of new studies and evidence syntheses spanning multiple countries and continents. Future endeavours on adolescent transitions will need to build on these findings, address its shortcomings, and tackle the questions introduced in the call that remains to be addressed.

Acknowledgements TG is funded by the Fonds de Recherche $d u$ Québec-Santé (FRQ-S).

\section{Compliance with ethical standards}

Conflict of interest I declare having no conflict of interest.

\section{References}

Baggio S, Studer J, Fructuoso A, Grazioli VS, Heller P, Wolff H, Gmel G, Perroud N (2018) Does level of attention deficithyperactivity disorder symptoms predicts poor transition into adulthood? Int J Public Health. https://doi.org/10.1007/s00038018-1147-x

De Looze M, van Dorsselaer S, Stevens G, Boniel-Nissim M, Vieno A, van den Eijnden R (2018) The decline in adolescent substance use across Europe and North America in the early 21st century: a result of the digital revolution? Int J Public Health

Furstenberg FF (2015) Becoming adults: challenges in the transition to adult roles. Am J Orthopsychiatry 85(5S):S14-S21

Johnson MK, Crosnoe R, Elder GH (2011) Insights on Adolescence from a life course perspective. J Res Adolesc 21(1):273-280

Masa R, Graham L, Khan Z, Chowa G, Patel L (2018) Food insecurity, sexual risk taking, and sexual victimization in Ghanaian adolescents and young south African adults. Int J Public Health. https://doi.org/10.1007/s00038-018-1155-x

Public Health Agency of Canada (PHAC) (2011) The Chief Public Health Officer's Report on the State of Public Health in Canada, 2011: youth and young adults-life in transition. Public Health Agency of Canada. https://www.canada.ca/content/dam/phacaspc/migration/phac-aspc/cphorsphc-respcacsp/2011/pdf/cphoresp-2011-eng.pdf. Accessed on 21 Dec 2018

Sawyer SM, Azzopardi PS, Wickremarathne D, Patton GC (2018) The age of adolescence. Lancet Child Adolesc Health 2(3):223-228

Publisher's Note Springer Nature remains neutral with regard to jurisdictional claims in published maps and institutional affiliations. 